\title{
Análise de uma experiência em formação para a comunicação popular e comunitária junto às lideranças de movimentos sociais em Londrina/PR
}

\author{
Analysis of a training experience for popular and community communication with the \\ leaderships of social movements in Londrina/PR
}

\author{
Rozinaldo Antonio Miani * \\ Suellen do Carmo ** \\ Angélica Tamy Nakane ***
}

\begin{abstract}
Resumo:
Como parte da realização de um projeto integrado de pesquisa e extensão cadastrado junto à Universidade Estadual de Londrina (UEL), foi realizado o Curso de Formação em Comunicação Popular e Comunitária durante o ano de 2016. A atividade foi realizada em quatro etapas e direcionada às lideranças e ativistas dos movimentos sociais de Londrina e região com o objetivo de proporcionar um espaço de formação em relação à importância da comunicação para a concretização dos objetivos estratégicos de movimentos sociais e movimentos populares. Os principais temas discutidos foram "Papel Estratégico da Comunicação", "Política de Comunicação" e "Planejamento Participativo". Nesse sentido, esse artigo tem como objetivo apresentar e analisar a referida experiência e refletir sobre a importância política da comunicação para a promoção de processos de participação popular.
\end{abstract}

Palavras-Chave: Comunicação popular e comunitária. Movimentos sociais. Formação. Londrina. UEL.

\begin{abstract}
:
As part of the realization of an integrated research and extension project registered with the State University of Londrina (UEL), the Training Course in Popular and Community Communication was held during the year 2016. The activity was carried out in four stages and directed to the leaderships and activists of the social movements of Londrina and region with the objective of providing a training space in relation to the importance of communication for the achievement of the strategic objectives of social movements and popular movements. The main topics discussed were "Strategic Communication Paper", "Communication Policy" and "Participatory Planning". In this sense, this article aims to present and analyze this experience and reflect on the political importance of communication for the promotion of popular participation processes.
\end{abstract}

Key-words: Popular and community communication. Social movements. Formation. Londrina. UEL.

\footnotetext{
* Doutor em História. Pós-doutor em Comunicação pela ECA/USP. Professor do Departamento de Comunicação e vice-coordenador do Programa de Mestrado em Comunicação da UEL. E-mail: mianirozinaldo@gmail.com

** Mestranda em Comunicação pela Universidade Estadual de Londrina. Graduada em Relações Públicas pela UEL. E-mail: su.carmo@hotmail.com

*** Graduada em Relações Públicas pela Universidade Estadual de Londrina. E-mail: tamynakane@gmail.com
} 


\section{Introdução}

Desde o final da década de 1970, a trajetória dos movimentos sociais e dos movimentos populares no Brasil foi marcada por momentos de ascensão e refluxo. A vigorosa retomada das lutas sociais e populares durante os anos finais do período da ditadura civil-militar (1964-1985) e a emergência de organizações sociais e políticas que atuaram decisivamente para a consolidação do processo de "redemocratização" do país (SADER, 1988) contrasta com a predominante apatia que tem provocado uma paralisia dos movimentos sociais desde a virada do século.

Com a abertura política, em fins da década de 1970, vimos emergir um conjunto de iniciativas políticas voltadas para a retomada de um processo democrático no país que resultaram na emergência de um "novo sindicalismo" - e a consequente fundação da Central Única dos Trabalhadores (CUT) - e no surgimento do Movimento dos Trabalhadores Rurais sem Terra (MST), dentre outras conquistas organizativas da classe trabalhadora. 0 fim do bipartidarismo (que vigorou durante o período ditatorial com a existência de apenas dois partidos, a Arena e o MDB) e a possibilidade de criação de outros partidos políticos também foram decisivos para a reconquista da democracia, que teve no Movimento pelas Diretas Já!, durante o ano de 1984, um dos momentos mais importantes da luta pelos direitos políticos.

Apesar da derrota do Movimento pelas Diretas Já! ${ }^{1}$, as organizações sociais e políticas, em franca ascensão e fortalecimento, não esmoreceram em seu objetivo de consolidar o processo de "redemocratização" da sociedade. Nesse sentido, conforme Rozinaldo Miani e Lorène Lairé,

[...] a sociedade civil intensificou sua organização em movimentos sociais e populares de toda ordem e nas mais diversas questões e temáticas sociais. Favorecidos por uma conjuntura política que proporcionava a possibilidade de explicitação dos reais problemas sociais brasileiros, principalmente por parte dos meios de comunicação de massa, as ações coletivas dos movimentos sociais tomaram vulto e tensionaram a sociedade brasileira a reconhecer a sua força política, que se mostrou efetiva até pelo menos o final daquela década (MIANI; LAIRÉ, 2010, p. 297).

Durante a segunda metade da década de 1980, foram registrados importantes processos políticos e organizativos que intensificaram a luta pela redemocratização, com

\footnotetext{
${ }^{1}$ Movimento civil de apoio à emenda constitucional apresentada pelo deputado Dante de Oliveira que previa o restabelecimento das eleições diretas para presidente da República. A emenda foi votada em 25 de abril de 1984 e faltaram 22 votos para que o projeto fosse aprovado pela Câmara e pudesse seguir para o Senado.
} 
Análise de uma experiência em formação para a comunicação popular e comunitária junto...

destaque para as mobilizações populares em torno da Assembleia Constituinte, entre 1985 e 1988, e a criação da Pró-Central dos Movimentos Populares, em 1989,

Porém, no início da década de 1990, em razão de uma conjuntura desfavorável, marcada por crises econômicas e políticas, associadas a uma desmobilização das forças populares como decorrência do desânimo que se abateu sobre as lideranças e bases dos movimentos populares pela derrota eleitoral do projeto da Frente Brasil Popular, representado pela candidatura de Lula, e também pelas consequências da condução política do governo Fernando Collor de Mello, houve um refluxo dos movimentos populares e, em contrapartida, a emergência de um conjunto de organizações sociais de outra natureza. Esse cenário foi assim descrito por Gohn:

\begin{abstract}
Os anos 90 redefiniram novamente o cenário das lutas sociais no Brasil [...]. Os movimentos sociais populares dos anos $70 / 80$ se alteram substancialmente. Alguns entram em crise: de militância, de mobilização, de participação cotidiana em atividades organizadas, de credibilidade nas políticas públicas, de confiabilidade e legitimidade junto à própria população. Surgem novos movimentos sociais, centrados mais em questões éticas ou de revalorização da vida humana. [...] Criamse movimentos nacionais a partir de instituições e organizações de espectro plural, ou de figuras carismáticas, como o caso de Betinho na Ação da Cidadania contra a Fome, a Miséria a pela Vida (GOHN, 1995, p. 128).
\end{abstract}

Já a partir da segunda metade da década de 1990, e até os dias atuais, a prática dos movimentos sociais no Brasil consolidou uma tendência que vinha sendo manifestada desde o início da década de 1990, ou seja, os movimentos sociais marcados por lutas cívicas ou cidadãs passaram a substituir os movimentos populares, de natureza classista, e protagonizaram uma nova configuração na correlação de forças políticas na sociedade brasileira. As Organizações Não Governamentais (ONGs) se constituíram como novos atores sociais e capitanearam as principais formas de organização da sociedade civil, viabilizando processos de parcerias com o Estado e com a iniciativa privada, resultando, dentre outras implicações, num processo de despolitização das organizações sociais.

Uma "sacudida" nessa conjuntura foi produzida por ocasião das manifestações e dos protestos de rua que marcaram o Brasil durante o ano de 2013 e, mais recentemente, pela mobilização social e popular em reação ao "golpe de 2016" 2 patrocinado por representantes do Legislativo e do Judiciário brasileiros, com apoio decisivo da mídia burguesa, rompendo um pouco à impassibilidade que tomava conta da sociedade brasileira

\footnotetext{
2 De acordo com Michael Löwy, "golpe de Estado pseudolegal, 'constitucional', 'institucional', parlamentar ou o que se preferir. Mas golpe de Estado" (LÖWY, 2016).
} 
e recolocou o tema dos movimentos sociais na pauta dos debates sociais e políticos. Porém, esse debate passa, necessariamente, pela tarefa de estabelecer com maior precisão a amplitude, bem como, as particularidades das novas formas de organização social que compõem o universo do que se têm caracterizado como "movimentos sociais".

Em termos regionais e locais se carece de pesquisas e estudos que mostrem e analisem a história e a atualidade dos movimentos sociais e dos movimentos populares e, mais do que isso, que consigam sistematizar suas conquistas e avaliar criticamente os seus próprios desafios e limites. Dentre as iniciativas que se propuseram a colaborar nesse sentido, destacamos o projeto integrado de pesquisa e extensão intitulado "O papel estratégico da comunicação popular e comunitária nos processos de organização e mobilização dos movimentos populares no Estado do Paraná", desenvolvido pelo Departamento de Comunicação da Universidade Estadual de Londrina (UEL) entre os anos de 2013 e 2017

A partir da realização de uma análise da realidade sociopolítica dos movimentos sociais no Estado do Paraná, o projeto teve como objetivo desenvolver um processo de formação em comunicação voltado para dirigentes, lideranças e ativistas de movimentos sociais e movimentos populares de Londrina e região por meio de oficinas de comunicação popular e comunitária (MIANI, 2013).

Nesse sentido, o objetivo desse artigo é apresentar e analisar a experiência do Curso de Formação em Comunicação Popular e Comunitária, realizado durante o ano de 2016 na Universidade Estadual de Londrina, e sua contribuição para o debate da participação popular. Iniciou-se a reflexão apresentando as principais características do referido projeto integrado de pesquisa e extensão, bem como uma descrição sucinta das etapas do referido Curso de Formação. Por fim, fez-se alguns apontamentos reflexivos sobre a importância política da comunicação para os movimentos sociais enfatizando a potencialidade dos processos de produção comunicativa como exercício de participação popular.

\section{Projeto Integrado Debate a Realidade dos Movimentos Sociais}

O projeto integrado de pesquisa e extensão intitulado "O papel estratégico da comunicação popular e comunitária nos processos de organização e mobilização dos 
movimentos populares no Estado do Paraná" foi desenvolvido junto ao Departamento de Comunicação da Universidade Estadual de Londrina entre os anos de 2013 e 2017 e teve como objetivo realizar uma análise da realidade sociopolítica dos movimentos sociais, movimentos populares e suas organizações de articulação política nacional, atuantes no Estado do Paraná, bem como de suas concepções e práticas comunicativas. Com base nas análises e de acordo com a metodologia da pesquisa participante e de procedimentos políticos da extensão universitária, o projeto promoveu um processo de sensibilização e, posteriormente, de formação de dirigentes, lideranças e ativistas de movimentos sociais em relação à importância estratégica da comunicação por meio do Curso de Formação em Comunicação Popular e Comunitária.

No tempo de desenvolvimento do projeto foram realizadas diversas atividades. As primeiras ações foram relacionadas à pesquisa, com levantamento bibliográfico e documental e estudos teórico-conceituais com o objetivo de debater a respeito dos temas relacionados aos objetivos geral e específicos do projeto, em especial, sobre as concepções, a história e a atualidade dos movimentos sociais e dos movimentos populares, tomando por base, principalmente, as contribuições de Ilse Scherer-Warren $(1984 ; 2014)$ e de Euclides André Mance $(1991 ; 2007)$.

A respeito do conceito de movimentos sociais, partimos da definição apresentada e desenvolvida por Scherer-Warren (1984). Para a autora, um movimento social deve ser entendido como:

[...] uma ação grupal transformadora (a práxis) voltada para a realização dos mesmos objetivos (o projeto), sob a orientação mais ou menos consciente de princípios valorativos comuns (a ideologia) e sob uma organização mais ou menos definida (a organização e sua direção) (SCHERER-WARREN, 1984, p. 20).

Por sua vez, Mance (1991) apresentou uma contribuição decisiva para que se compreendesse os movimentos populares, entendidos como uma parcela dos movimentos sociais, e que se tornou a principal referência para os debates que resultaram na criação da Central dos Movimentos Populares (CMP), ${ }^{3}$ ocorrida em outubro de 1993. Para Mance,

\footnotetext{
3 Conforme apresentado em documento oficial, "a CMP tem como objetivo construir um projeto popular alternativo, rumo ao socialismo, organizando, articulando e mobilizando os movimentos populares no combate ao projeto neoliberal, tornando-se uma referência na luta por políticas públicas com a participação popular" (CENTRAL DE MOVIMENTOS POPULARES, 2000, p. 9).
} 
O termo MOVIMENTOS POPULARES por sua vez, caracteriza uma parcela dos movimentos sociais. Este conceito não abrange o movimento sindical, englobando os demais movimentos que tenham nas camadas populares seu sujeito e sua base de constituição. Por camadas populares entende-se os setores explorados, dominados e oprimidos. Tais movimentos, entretanto, podem ter um cunho conservador ou revolucionário, dependendo de sua concepção e práticas adotadas para a conquista de seus interesses que podem ser apenas imediatos ou mais estratégicos (MANCE, 1991, p. 3).

Essas referências, bem como algumas contribuições pontuais de Maria da Glória Gohn (1995; 2001), ajudou a sistematizar uma concepção de movimento popular que se tornou um parâmetro para as reflexões desenvolvidas durante o projeto. Nesse sentido,

\begin{abstract}
Os movimentos populares são entendidos como a variedade de formas de organização autônoma dos setores das classes subalternas que atuam invariavelmente na perspectiva de enfrentamento ao sistema capitalista e ao seu instrumento de dominação: o Estado. Esses movimentos atuam sobre as contradições entre as classes subalternas e as condições de reprodução social da força de trabalho patrocinadas pelo Estado. Incluem-se na definição de movimentos populares todos os movimentos, grupos e organizações que atuam na área de circulação e consumo de mercadorias e de bens de uso coletivo (saúde, educação, transporte, abastecimento, saneamento básico), bem como os que se confrontam diretamente com o capital na área de reprodução social (exemplo dos sem terra e sem teto) e ainda aqueles que enfrentam a ideologia de dominação nas lutas políticas do cotidiano (ecológicos, direitos humanos, grupos de teatro). Nestes casos, exige-se que o movimento popular seja autônomo, ou seja, sem vínculos de dependência com Estado, empresa privada, Igreja, instituições de assessoria (ONGs). O fato de algumas organizações terem seu centro de decisão situados, em última instância, fora de seu próprio âmbito, os qualificaria em outra natureza de movimentos (MIANI, 2008).
\end{abstract}

Apesar de, ainda, os movimentos populares se apresentarem, para compreensão, como a principal forma de organização estratégica das classes subalternas para os processos de disputa de hegemonias ${ }^{4}$ é preciso reconhecer que, na atualidade, há uma pluralidade e uma complexidade em relação às formas de organização e de atuação dos movimentos sociais que precisam ser consideradas e entendidas. Scherer-Warren, inclusive, apresenta

\footnotetext{
${ }^{4}$ A referência ao processo de disputa de hegemonias implica compreender o próprio conceito de hegemonia. Para tanto, tomamos por base o conceito de hegemonia do pensador marxista italiano Antonio Gramsci, sistematizado por Dênis de Moraes, que afirma que "a hegemonia pressupõe a conquista do consenso e da liderança cultural e político-ideológica de uma classe ou bloco de classes sobre as outras [...] [e] não deve ser entendida nos limites de uma coerção pura e simples, pois inclui a direção cultural e o consentimento social a um universo de conviç̧ões, normas morais e regras de conduta, assim como a destruição e a superação de outras crenças e sentimentos diante da vida e do mundo" (MORAES, 2010, p.54-55). A disputa de hegemonias, portanto - além de implicar embates na ordem da estrutura econômica e da organização política -, também passa, necessariamente, por uma disputa no campo simbólico e cultural da sociedade e, nesse sentido, a formação de um novo consenso com vistas a uma nova ordem societária "depende da capacidade das classes subalternas de se converterem em força política efetiva, forjando uma unidade de objetivos que resulte na coordenação de iniciativas e princípios ideológicos" (MORAES, 2010, p.56). É nesse contexto que os movimentos populares, ao nosso ver, se constituem uma condição estratégica.
} 
Análise de uma experiência em formação para a comunicação popular e comunitária junto...

uma tipologia que cumpre bem a difícil tarefa de "diferenciar as formas de lutas cidadãs coletivas, referenciando-se especialmente na sociedade brasileira contemporânea a fim de compreender suas dinâmicas políticas internas e seu papel político na sociedade como um todo" (SCHERER-WARREN, 2014, p. 13).

A partir dessas considerações teóricas, a equipe do projeto realizou um mapeamento preliminar da realidade dos movimentos sociais e dos movimentos populares no estado do Paraná, bem como um levantamento de suas respectivas práticas comunicativas (MIANI, 2015). O mapeamento incidiu na sua quase totalidade às organizações sociais e populares de Londrina e região.

As atividades de pesquisa seguiram por todo o tempo de duração do projeto, porém, a partir do segundo ano de sua realização, as atividades de extensão ganharam maior relevância. A primeira atividade de extensão realizada foi a organização de uma oficina com representantes de rádios comunitárias da região norte do Paraná que aconteceu em setembro de 2014. Apesar de não fazer parte dos objetivos iniciais do projeto, essa atividade foi proposta por se tratar de uma ação de extensão (necessária para a própria natureza do projeto) e, principalmente, por considerar que tais organizações poderiam desempenhar papel estratégico para a atuação dos movimentos sociais, além de se tratar de um espaço comunicativo com atuação local e, portanto, passível de apropriação por parte dos movimentos sociais no cumprimento de seus respectivos objetivos (MIANI, 2017).

As rádios comunitárias - apesar de se verificar que em muitos casos há desvios de conduta e mesmo de cumprimento de finalidades - podem funcionar como importantes organizações de desenvolvimento sociopolítico local. Considerando que as emissoras comunitárias são organizadas e gestadas por representantes de movimentos sociais e organizações populares, proporcionar um espaço de formação para os integrantes das rádios comunitárias visava aproximar as lideranças populares de tais emissoras de rádio para que, assim, pudessem reconhecê-las como espaço para atuação política local. Sobre a importância política das rádios comunitárias, Rozinaldo Miani afirma:

Enfim, as rádios comunitárias se constituem como uma importante estratégia política no processo de construção de um poder popular. Fazer desses veículos comunitários um espaço de participação e de exercício da democracia, bem como reconhecê-los como uma arena onde se promovem processos de disputa de hegemonias é uma tarefa urgente para quem deseja e acredita em uma efetiva transformação social (MIANI, 2017, p. 70). 
A partir de tal convicção, foram contatadas mais de trinta emissoras de rádio comunitária da região de Londrina para participarem da oficina e, apesar da baixa participação, a atividade foi importante para poder avaliar as dificuldades em relação ao processo de mobilização de lideranças populares para a concretização dos objetivos do projeto acadêmico.

Após a realização da oficina com as rádios comunitárias, foram iniciados os contatos com os movimentos sociais do Paraná, exclusivamente de Londrina e região, para a realização de uma Oficina de Comunicação Popular e Comunitária com o objetivo de sensibilização dos dirigentes e lideranças dos movimentos sociais a respeito da importância estratégica da comunicação. A oficina foi realizada em fevereiro de 2016 e contou com uma participação bastante representativa. Estiveram presentes representantes dos seguintes movimentos e/ou organizações: Movimento Nacional de População de Rua - Núcleo Londrina (MNPR), Movimento Hip Hop, Movimento Nacional de Direitos Humanos - Londrina (MNDH), Comitê do Passe Livre Londrina, Levante Popular da Juventude, Central de Movimentos Populares (CMP), Central Única de Favelas (CUFA), Rede de Mulheres Negras, Associação de Ogans, Fórum Paranaense de Educação de Jovens e Adultos da Região de Londrina (Fórum EJA-Londrina), Associação Londrinense Interdisciplinar de Aids (Alia), Cooperativa de Catadores de Materiais Recicláveis e Resíduos Sólidos da Região Metropolitana de Londrina (Cooper Região), União dos Deficientes Físicos de Cambé (Unidef), União Municipal das Associações de Moradores de Londrina (Unimol) e Lutas Assessoria Jurídica Universitária Popular.

Durante a realização da oficina houve um primeiro momento de integração entre os participantes e de levantamento de expectativas. A equipe de coordenação apresentou os objetivos da oficina e iniciou os debates com um relato das atividades desenvolvidas pelo projeto integrado. Foi apresentada uma discussão conceitual a respeito de movimentos sociais e movimentos populares e um panorama da realidade dos movimentos e organizações sociais de Londrina e região, resultado do estudo e do mapeamento desenvolvido pela equipe do projeto.

Para entrar no debate específico da comunicação foi proposta uma atividade em que os participantes deveriam apresentar um diagnóstico das práticas comunicativas de suas respectivas organizações. As questões orientadoras foram: "quais as práticas comunicativas desenvolvidas pelo movimento?" e "quais práticas comunicativas o movimento gostaria de 
Análise de uma experiência em formação para a comunicação popular e comunitária junto...

desenvolver?". O objetivo da atividade era identificar e descrever as práticas comunicativas desenvolvidas, bem como apresentar as demandas comunicativas de cada um dos movimentos presentes.

Dando continuidade ao propósito de sensibilização dos dirigentes, lideranças e ativistas dos movimentos sociais em relação à importância da comunicação, outra atividade foi proposta, dessa vez para que, em grupo, os participantes da oficina debatessem a partir das seguintes questões: "como você entende o papel estratégico da comunicação para as organizações e movimentos sociais?" e "quais as principais características que deve ter a comunicação produzida pelos movimentos sociais?". O objetivo era diagnosticar a concepção de comunicação defendida pelas lideranças populares. Na sequência, a equipe de coordenação da oficina apresentou uma análise a respeito dos pressupostos da comunicação popular e comunitária, da condição estratégica da comunicação para os movimentos sociais e da importância da construção de uma política de comunicação.

A respeito da comunicação popular e comunitária, deve-se ressaltar que a opção por essa perspectiva comunicacional como diretriz política para a realização de um processo de formação junto aos dirigentes, lideranças e ativistas dos movimentos sociais se justifica por se tratar, segundo Rozinaldo Miani, de uma comunicação

[...] de natureza contra-hegemônica, classista, comprometida com a perspectiva de mudança da ordem societária, constituída por meio de processos participativos, de valorização das subjetividades e potencializando um movimento de desalienação. Reconhecemos, ainda, que a Comunicação Popular e Comunitária é produzida, predominantemente, no âmbito das organizações sociais e movimentos populares de perspectiva (tática ou estratégica) anticapitalistas (MIANI, 2016, p. 11).

Ao final da oficina, a avaliação dos participantes foi bastante positiva, reconhecendo a necessidade de que a comunicação ocupe mais espaço nos debates e nas ações políticas dos movimentos, principalmente, investindo esforços para o planejamento e execução de uma política de comunicação. Houve, ainda, uma manifestação unânime sobre a necessidade de continuidade das discussões sobre o tema de maneira mais ampliada e aprofundada. Diante disso, foi proposta a organização de um Curso de Formação em Comunicação Popular e Comunitária. 


\section{Curso de Formação em Comunicação para as Lideranças Populares}

A proposta do Curso de Formação em Comunicação Popular e Comunitária foi formalizada como curso de extensão cadastrado junto à Pró-Reitoria de Extensão (Proex) da Universidade Estadual de Londrina. O curso foi organizado para ser cumprido em quatro etapas, com encontros mensais, entre maio e agosto de 2016.

Conforme disseminado nos materiais e ações de divulgação, a intenção era que o curso contasse com a participação de representantes indicados oficialmente pelos movimentos e organizações sociais, com a perspectiva de participação em todas as etapas. Alguns participantes, de fato, tiveram presença na maioria das etapas, porém, em vários casos, a participação acabou sendo mais espontânea e individual. O propósito com essa intenção era que os participantes pudessem se tornar referências para o próprio movimento no debate e no encaminhamento das questões relacionadas à comunicação, inclusive, na elaboração da política de comunicação do respectivo movimento.

Diante das circunstâncias, a dinâmica de cada uma das etapas contava sempre com a apresentação dos participantes e da programação a ser cumprida no dia; a partir da segunda etapa, também era feita uma breve síntese das etapas anteriores e a verificação do cumprimento das tarefas que eram designadas para os participantes realizarem entre uma etapa e outra do curso. Havia sempre uma dinâmica para dar início às reflexões da temática da etapa, uma atividade em grupo para proporcionar a reflexão coletiva dos participantes e, por fim, uma exposição teórica a partir de um fragmento de texto, que era entregue a todos os participantes, e que servia de subsídio para a respectiva reflexão conceitual.

A primeira etapa do curso teve como tema "O Papel Estratégico da Comunicação". Na dinâmica inicial, o objetivo foi vivenciar o "desafio de se comunicar", mostrando que a comunicação é um processo difícil e desafiador e que, muitas vezes, se não for realizada de maneira adequada, pode gerar muitas dificuldades e produzir entendimentos muito diferentes, até mesmo antagônicos, entre os sujeitos dos processos comunicativos. A dinâmica foi o pretexto para a realização de uma discussão coletiva, em que os participantes deveriam refletir sobre "o que é comunicação?". Após o trabalho em grupo e a socialização das reflexões, fez-se um debate sobre a importância estratégica da comunicação para os movimentos sociais, afirmando à necessidade de se utilizar dessa ferramenta nos processos 
de disputa de hegemonias. Por fim, foram feitas as avaliações, os encaminhamentos da tarefa a ser apresentada na etapa seguinte e o encerramento da atividade.

Em relação ao debate sobre a comunicação popular e comunitária foram apresentados os seus principais pressupostos teórico-ideológicos, que indicam tratar-se de uma comunicação que atua a serviço das classes subalternas, com o objetivo de transformação social. A esse respeito, afirma Miani:

\begin{abstract}
A Comunicação Popular e Comunitária se situa no terreno da transformação social e, portanto, da ação política. Nesse sentido, dado o seu caráter de compromisso com o processo de transformação numa perspectiva anticapitalista, a Comunicação Popular e Comunitária se coloca como instrumento da luta de classes, servindo às classes subalternas como instrumento contra-hegemônico de atuação e de construção de novos valores sociopolíticos identificados pela perspectiva da Educação Popular (MIANI, 2010).
\end{abstract}

Na segunda etapa, o tema definido foi "Política de Comunicação". A dinâmica utilizada foi a produção de um "desenho desconexo", que serviu para refletir sobre a necessidade de se realizar as atividades de maneira coletiva e dialogada, associando essa reflexão à importância da construção de uma política de comunicação, pois sem isso a comunicação acaba sendo realizada de maneira fragmentada e desconexa, muitas vezes, sem objetivos definidos e com resultados pouco produtivos. Na sequência, os participantes foram divididos em grupos para refletirem sobre as seguintes questões: "qual a importância de uma política de comunicação? e "o que é necessário para uma política de comunicação?". Foram distribuídos cartões com possíveis respostas para que os grupos escolhessem aquelas que melhor pudessem responder às questões apresentadas. Em seguida, houve uma reflexão coletiva sobre a importância da elaboração e execução de uma política de comunicação e de como ela deve ser parte do projeto político da organização, contribuindo para que os seus objetivos sejam alcançados. Encerrando a segunda etapa, foram feitas as avaliações e o encaminhamento da tarefa para a próxima etapa.

No que se refere à política de comunicação é preciso que os movimentos sociais compreendam que, antes de tudo, a comunicação deve ser assumida como parte do próprio projeto político da organização. A esse respeito, Alice Mitika Koshiyama afirma:

As políticas de comunicação fundamentam-se em valores ético-políticos e tratam de diretrizes permanentes e não apenas de problemas episódicos. A clareza sobre os valores a serem defendidos e a definição quanto às ações concretas na transmissão e multiplicação do saber especializado são parte de uma política (KOSHIYAMA, 1995, p. 117). 
Rozinaldo Miani e Ludmilla Andrade Fregonesi (2008) apresentaram uma sistematização a respeito do conceito de "política de comunicação" que subsidiou nossas reflexões na referida etapa do curso de formação:

\footnotetext{
Política de Comunicação se define por um conjunto de diretrizes políticas, de natureza permanente e orgânica, sobre a comunicação de uma determinada organização social, invariavelmente materializado por práticas e produções comunicativas planejadas e executadas de forma participativa e dentro de parâmetros de eficiência e eficácia, desempenhando papel formativo e informativo no processo de Educação Popular, com vistas à conscientização, dos sujeitos envolvidos direta e indiretamente pelos objetivos estratégicos da organização (MIANI; FREGONESI, 2008, p. 60-61).
}

O tema da terceira etapa do Curso de Formação em Comunicação Popular e Comunitária foi "Planejamento Participativo". O objetivo com esse tema foi refletir com as lideranças populares que a elaboração de uma política de comunicação deve se pautar por princípios democráticos e participativos, em que todos devem contribuir para que a comunicação represente o máximo possível as diversas perspectivas dos integrantes do movimento, obviamente submetidas aos princípios e posições políticas do movimento. Para iniciar as atividades foi realizada uma dinâmica que procurou mostrar as diferentes condições sociais e identitárias dos participantes e fazer compreender, que essas diferenças não podem ser negligenciadas quando da organização do planejamento do movimento e de sua política de comunicação. Como atividade de grupo, os participantes foram divididos por movimentos para responder às seguintes questões: "com quais públicos o seu movimento se relaciona?" e "quais as práticas comunicativas utilizadas para o estabelecimento dessas relações?". Essa reflexão se fazia necessária, pois em um planejamento de comunicação é fundamental definir com precisão com quais públicos o movimento se relaciona e qual a forma de comunicação mais adequada para cada um dos respectivos públicos. Depois da apresentação de cada grupo foi realizada uma exposição sobre a importância do planejamento participativo para a elaboração de uma política de comunicação. Ao final, foram feitas as avaliações e os encaminhamentos para a última etapa.

O planejamento participativo é considerado um instrumental decisivo para o desenvolvimento de uma política de comunicação, principalmente, em se tratando de comunicação popular e comunitária. A esse respeito, Rozinaldo Miani e Camila Frazatti Rodrigues Felício afirmam: 


\begin{abstract}
A Comunicação Popular e Comunitária, por sua vez, enquanto concepção e prática de um fazer comunicativo de natureza contra-hegemônica, também visa, para além de seus objetivos imediatos do comunicar numa perspectiva político-ideológica comprometida com os interesses das classes subalternas, conduzir os sujeitos protagonistas das práticas comunicativas a um processo de emancipação e de "desalienação" por meio de uma atuação política marcada pela valorização dos processos participativos. No contexto dos movimentos sociais, e de maneira ainda mais específica dos movimentos populares, o planejamento participativo se apresenta como o instrumental técnico e político de planejamento mais apropriado para o estabelecimento de uma política de comunicação para tais organizações sociopolíticas (MIANI; FELícIO, 2009, p. 10).
\end{abstract}

A quarta e última etapa do curso tinha como objetivo realizar uma "Oficina de Comunicação". O propósito era indicar o conjunto de possibilidades comunicativas que os movimentos podem desenvolver no contexto de suas respectivas políticas de comunicação e, principalmente, oferecer aos participantes do curso algumas orientações gerais para a produção de veículos comunicativos impressos ou digitais. Nessa etapa, a desmobilização foi geral e apenas representantes de uma única organização compareceu. Diante da situação, ficou decidido que a oficina não aconteceria naquele momento, pois seria pouco produtivo, e que a equipe do projeto integrado, responsável pelo curso, ficaria à disposição para realizar a oficina com o coletivo geral daquela organização (bem como, de quaisquer outras organizações também interessadas em realizar oficinas de produção em comunicação ${ }^{5}$ ) em data a ser indicada por eles.

Como desdobramento do Curso de Formação em Comunicação Popular e Comunitária foi organizada uma cartilha com o registro e a sistematização de todas as etapas do curso que deverá ser reproduzida e entregue às organizações e movimentos que participaram tanto da oficina de sensibilização quanto do curso de formação. Esse material pretende servir como subsídio para contribuir com a continuidade das discussões dos movimentos sociais sobre a questão da comunicação.

O projeto integrado de pesquisa e extensão já está encerrado, mas a equipe que participou do projeto se colocou à disposição de qualquer organização ou movimento social que queira construir sua política de comunicação, afinal o compromisso político que deriva dos resultados de uma ação acadêmica de pesquisa ou extensão não devem se restringir ao

\footnotetext{
${ }^{5}$ Diante dessa possibilidade oferecida pelo projeto integrado, o Fórum Paranaense de Educação de Jovens e Adultos de Londrina, no contexto do Curso de Formação para Educadores e Educadoras Estaduais e Municipais da EJA, incluiu como um dos temas "Comunicação Popular e Comunitária no contexto escolar da EJA", cuja oficina ocorreu no dia 27 de maio de 2017 e que foi ministrada por Rozinaldo Miani.
} 
tempo do projeto, mas às necessidades e demandas da própria realidade, neste caso, dos movimentos sociais e dos movimentos populares.

\section{A Importância da Comunicação para a Promoção da Participação}

A participação se constitui como um dos pressupostos teórico-políticos fundamentais para a Comunicação Popular e Comunitária, pois, nesse contexto, ela se apresenta como um elemento articulador dos processos de produção comunicativa. Ou seja, a comunicação popular e comunitária exige a constituição de processos participativos para a sua realização, seja na organização do planejamento participativo para a construção da política de comunicação, seja na produção específica de cada uma das práticas comunicativas.

Sobre o conceito de participação, tomamos como referências as contribuições apresentadas por Pedro Demo (1999) e, principalmente, Cicilia Maria Krohling Peruzzo (1995; 1998). Para a referida autora, a compreensão da participação passa pela identificação de níveis e modalidades de participação que, no limite, estão diretamente relacionados ao exercício do poder. Sobre essa questão afirma Peruzzo: "participação diz respeito à democracia, ao acesso a algo, à partilha de algo, mas se relaciona com o exercício do poder" (PERUZZO, 1995, p. 143). Peruzzo enfatiza, ainda, a importância da participação como processo educativo:

\footnotetext{
A participação popular pode facilitar o devir de uma nova práxis da comunicação. A participação e a comunicação representam uma necessidade no processo de constituição de uma cultura democrática de ampliação dos direitos de cidadania e da conquista da hegemonia, na construção de uma sociedade que veja o ser humano como força motivadora, propulsora e receptora dos benefícios do desenvolvimento histórico (PERUZZO, 1998, p. 296).
}

Em suas reflexões sobre a participação no contexto de práticas comunicativas, Peruzzo (1995) apresenta três modalidades de participação que compreendem, cada uma delas, a diferentes condições de exercício do poder. A primeira modalidade é a nãoparticipação e o poder praticado é de tipo autoritário. A segunda modalidade é a participação controlada e o poder, apesar de permanecer autoritário (pois as principais estruturas de poder permanecem intactas), apresenta-se como democrático. Por fim, a terceira modalidade é a participação-poder e, nesse caso, o exercício do poder é partilhado. 
Sobre as modalidades de participação e, mais especificamente, sobre a participação-poder, Peruzzo afirma:

Diante das várias possibilidades de se participar, a opção entre uma delas implica numa atitude política e metodológica. Se a motivação fundamental for o interesse político pela autoemancipação das comunidades e pela participação das pessoas enquanto sujeito e não objeto, a forma mais apropriada seria a participação-poder (PERUZZO, 1995, p. 156).

Com relação ao desafio de fazer do processo de produção comunicativa um caminho para a promoção da participação, Rozinaldo Miani argumenta:

[...] no contexto da Comunicação Popular e Comunitária, a participação (principalmente, na modalidade da participação-poder) se apresenta como uma estratégia para promover a aglutinação e articulação dos sujeitos de um determinado grupo social, favorecendo a intensificação de vínculos entre eles, de valorização das subjetividades e de desenvolvimento de um espírito coletivo e de solidariedade entre todos, na perspectiva de promover a emancipação e a autonomia dos sujeitos. Além disso, a Comunicação Popular e Comunitária se orienta no sentido de aproximar os envolvidos nos processos de comunicação, não somente visando aproximar emissor e receptor, mas fazendo-os agentes de um mesmo movimento desierarquizado. Tudo isso, no entanto, sem perder de vista a perspectiva político-ideológica desse fazer comunicativo no contexto da luta de classes e de disputa de hegemonias (MIANI, 2015, p. 12-13).

Enfim, a realização do Curso de Formação em Comunicação Popular e Comunitária que foi oferecido aos dirigentes, lideranças e ativistas dos movimentos sociais e demais organizações de Londrina e região visava, além de contribuir para disseminar a convicção da importância da comunicação para a concretização dos objetivos estratégicos de movimentos sociais e movimentos populares, potencializar o estabelecimento de condições apropriadas para o exercício da participação refletindo sobre a importância política da comunicação para a promoção de processos de participação popular.

\section{Considerações Finais}

A realização do Curso de Formação em Comunicação Popular e Comunitária, como parte do cumprimento do objetivo geral de um projeto integrado de pesquisa e extensão, se propunha a atender uma demanda política dos movimentos sociais em relação à necessidade de melhor compreender a importância estratégica da comunicação e, mais do que isso, de fomentar entre os dirigentes, lideranças e ativistas de movimentos e organizações sociais o reconhecimento da premência em se elaborar e por em prática uma política de comunicação. 
Apesar da realização de uma atividade prévia de sensibilização (oficina) que se mostrou decisiva para pautar o tema da comunicação entre os movimentos sociais, houve uma grande dificuldade na mobilização das lideranças populares para a participação no Curso de Formação, principalmente, numa condição de representante oficialmente indicado por sua respectiva organização. O interesse pelo tema da comunicação por parte dos movimentos sociais ainda se mostra uma demanda espontânea e individual.

Também podemos concluir que é preciso insistir no processo de formação de dirigentes e lideranças de organizações sociais em relação ao tema da comunicação, pois ainda não se desenvolveu o reconhecimento necessário quanto à importância estratégica da comunicação para a concretização dos objetivos programáticos de movimentos sociais e movimentos populares, nem mesmo em relação à importância do desenvolvimento de processos de produção comunicativa como potencializadores da participação popular.

Apesar do encerramento do projeto acadêmico é preciso reafirmar que quaisquer demandas derivadas dos movimentos sociais e movimentos populares no sentido de discutir o tema da comunicação ou, na melhor das hipóteses, de o movimento pretender elaborar a sua política de comunicação, não serão negligenciadas ou refugadas e poderão ser assumidas como desafio político por parte daqueles que participaram efetivamente do projeto (eventualmente até mesmo como um novo projeto de pesquisa ou extensão), pois a realização de um projeto acadêmico deve se constituir apenas como parte do compromisso político do sujeito social, na sua condição de pesquisador.

\section{Referências}

CENTRAL DE MOVIMENTOS POPULARES. Políticas públicas com participação popular. São Paulo: CMP, 2000.

DEMO, P. Participação é conquista. 3.ed. São Paulo: Cortez, 1999.

GOHN, M. G. História dos movimentos e lutas sociais: a construção da cidadania dos brasileiros. 2.ed. São Paulo: Loyola, 2001.

Teorias dos movimentos sociais: paradigmas clássicos e contemporâneos. São Paulo:

Loyola, 1995. 
KOSHIYAMA, A. M. A necessidade de uma política de comunicação. In: DIDONÉ, I. M.; MENEZES, J. E. O. (Org.). Comunicação e política: a ação conjunta das ONGs. São Paulo: Paulinas, 1995. p. 116-118.

LÖWY, M. O golpe de Estado de 2016 no Brasil. Blog da Boitempo, 17 maio de 2016. Disponível em: <https://blogdaboitempo.com.br/2016/05/17/michael-lowy-o-golpe-deestado-de-2016-no-brasil/>. Acesso em:22 set. 2017.

MANCE, E. A. Algumas concepções de movimento popular. Curitiba: Cefuria, 1991.

O papel estratégico do movimento popular para a democracia popular: o aprendizado dos anos 80 e 90. Curitiba: Instituto de Filosofia da Libertação, 2007. Disponível em: <http://www.solidarius.com.br/mance/biblioteca/movpop.pdf>.

MIANI, R. A. O papel das rádios comunitárias no contexto de desenvolvimento sociopolítico local no Paraná. Ação Midiática, Curitiba, n. 13, p. 53-74, jan./jun. 2017.

A constituição do campo da comunicação popular e comunitária. Londrina, 2016.

. Estudo exploratório sobre a presença da comunicação popular e comunitária nos movimentos sociais e populares do estado do Paraná. Revista Passagens, Fortaleza, v. 6, n. 2, p. 72-90, 2015.

O papel estratégico da Comunicação Popular e Comunitária nos processos de organização e mobilização dos movimentos populares no estado do Paraná, Londrina, 2013. (Projeto integrado de pesquisa e extensão apresentado junto ao Departamento de Comunicação da Universidade Estadual de Londrina).

.. Os pressupostos teórico-ideológicos da Comunicação Popular e Comunitária. In: SIMPÓSIO DE COMUNICAÇÃO POPULAR E COMUNITÁRIA, 1., 2010, Londrina. Anais... Londrina: UEL, 2010.

Apontamentos sobre a definição de movimento popular na atualidade. Londrina, 2008. (mimeo).

MIANI, R. A.; LAIRÉ, L. M. A comunicação como estratégia de organização e atuação política: o caso da Central de Movimentos Populares (CMP) Regional Londrina. In: BARBALHO, A.; FUSER, B.; COGO, D. (Org.). Comunicação para a cidadania: temas e aportes teóricometodológicos. São Paulo: Intercom, 2010. p. 295-312.

MIANI, R. A.; FELÍCIO, C. F. R. O planejamento participativo no contexto da Comunicação Popular e Comunitária. In: CONGRESSO BRASILEIRO DE CIÊNCIAS DA COMUNICAÇÃO, 32., Curitiba, set. 2009. Anais... Curitiba, 2009.

MIANI, R. A.; FREGONESI, L. A. A política de comunicação como fator de organização e mobilização dos movimentos sociais e populares. In: FUSER, Bruno (Org.). Comunicação para a cidadania: caminhos e impasses. Rio de Janeiro: E-papers, 2008. p. 53-63. 
MORAES, D. Comunicação, hegemonia e contra-hegemonia: a contribuição teórica de Gramsci. Debates, Porto Alegre, v. 4, n. 1, p. 54-77, jan.-jun. 2010.

PERUZZO, C. M. K. Comunicação nos movimentos populares: a participação na construção da cidadania. Petrópolis, RJ: Vozes, 1998.

Pistas para o estudo e a prática da comunicação comunitária participativa. In: PERUZZO, C. M. K. (Org.). Comunicação e culturas populares. São Paulo: Intercom, 1995. p. 143-162.

SADER, E. Quando novos personagens entraram em cena: experiências, falas e lutas dos trabalhadores da Grande São Paulo, 1970-80. Rio de Janeiro: Paz e Terra, 1988.

SCHERER-WARREN, I. Movimentos sociais: um ensaio de interpretação sociológica. Florianópolis: EDUFSC, 1984.

Dos movimentos sociais às manifestações de rua: o ativismo brasileiro no século XX. Política e Sociedade, Florianópolis, v. 13, n. 28, p. 13-34, set./dez. 2014. 